\title{
Evaluation of cartosat-1 satellite triangulation \& DSMs in varied terrain conditions
}

\author{
Ashutosh Bhardwaj ${ }^{1, *}$, R. S. Chaterjee ${ }^{1}$, Kamal Jain ${ }^{2}$ \\ ${ }^{1}$ Indian Institute of Remote Sensing (ISRO), Dehradun, India \\ ${ }^{2}$ Indian Institute of Technology, Roorkee, India
}

Email address:

ashutosh@iirs.gov.in (A. Bhardwaj)

To cite this article:

Ashutosh Bhardwaj, R. S. Chaterjee, Kamal Jain. Evaluation of Cartosat-1 Satellite Triangulation \& Dsms in Varied Terrain Conditions, Science Research. Vol. 1, No. 2, 2013, pp. 19-24. doi: 10.11648/j.sr.20130102.12

\begin{abstract}
Digital surface models (DSMs) and Digital elevation models (DEMs) has become inevitable input for many applications including various types of modeling problems besides photogrammetric product generation such as orthoimages and visualization. Automatically generated DSMs using image matching techniques are an efficient means to extract bare earth DEMs or DTMs for various applications including modeling. This paper highlights and evaluates the accuracy of satellite triangulation, and DEM generated from Cartosat-1 data by using Rational Polynomial Coefficient's (RPC's) provided with the Cartosat-1 data along with ground control points (GCPs) collected through differential Global Positioning System (DGPS) surveys. Three study sites were taken for evaluation of DSMs in different topographic conditions, namely, a) Dehradun, Uttarakhand characterized by relatively high undulating terrain comprising of shivalik hills in the south and higher Himalayas on the north, b) Jaipur, Rajasthan having more of urban and plain agriculture area with Aravalli ranges, and c) Kendrapara, Orissa which is having a plain terrain conditions with agriculture fields, river, and sparsely populated area. DGPS surveys were conducted at the three sites to collect ground control points (GCPs) for satellite triangulation \& subsequent analysis. The satellite triangulation resulted in RMSE of better than a pixel for all the three sites. The RMSE for DEM is varying from within a pixel for plain area to about four pixels for highly undulating terrain. The paper describes the positional and vertical accuracies achieved for cartosat-1 stereo data through photogrammetric process of satellite triangulation and Digital surface model generation in the three study sites having different topographic conditions.
\end{abstract}

Keywords: Satellite Triangulation, Digital Surface Model, Digital Elevation Model, Differential GPS survey, Ground Control Points, Rational Polynomial Coefficient's

\section{Introduction}

The scientific developments in the area of ground as well as space instrumentation such as GPS/GNSS, gyroscopes, star sensors, and INS/IMU are increasing the chances of better and better RPC based triangulation or even onboard triangulation on aerial as well as satellite platforms. Terrestrial photogrammetry and close range photogrammetry (CRP) are also fast developing with the new Structure from Motion (SfM) approach and fast computers [1]. Low height platforms like UAVs (unmanned aerial vehicles), ROVs (remotely operated vehicles) [2] are getting more attention and prominence for research work in photogrammetry and feature extraction as compared to earlier days. The collinearity equations forms the basis of all kind of photogrammetric applications whether aerial, satellite or terrestrial. Digital Surface Models (DSMs) offer the possibility of extracting the elevations of surface features to leave the ground surface DEM. Inherent limitation in accuracy assessment has been the use of limited GCPs, a DEM with higher resolution and quality can provide a better evaluation. However, such high resolutions DEMs are usually unavailable or do not have open access [3].

Cartosat-1 is the eleventh satellite, built in the Indian Remote Sensing (IRS) series and was launched on May 5, 2005. This sun synchronous satellite carries two pancharomatic (fore/aft) cameras that capture along-track stereoscopic images over a $30 \mathrm{~km}$ swath at $2.5 \mathrm{~m}$ ground resolution with 10 bit radiometric resolution enabling the creation of accurate 3D maps [4]. The large number of studies world over on cartosat-1emphasises on its success, both as a technology giving high geometric accuracy with its base-to-height $(\mathrm{b} / \mathrm{h})$ ratio of 0.62 and economics as it is priced very optimally for maximum usage for the benefit of humankind. In terms of technology and as a successor of 
ASTER and SPOT-5 (HRS), Cartosat-1 has proved its potential for photogrammetric applications particularly topographic mapping and visualization [5]. It has been followed now by ALOS PRISM having three cameras and Pleiadus-1A/1B satellite sensors. More new generation satellites are also going to be launced soon like the sentinel series of satellites and cartosat series of satellites. Most of these satellites will be based on the concept of rational polynomial coefficients (RPCs). The concept of RPC's has been introduced by IKONOS [6]. Many studies have carried out IKONOS stereo data analysis using Rational Function Model (RFM) for evaluating geometric accuracy [7], bundle adjustment [8], stereo feature extraction [9] and mapping [10]. The study of Cartosat-1 stereo data products reveals DEM accuracy of about $4 \mathrm{~m}[11,12]$ and its use in natural hazard applications [13,14]. Studies by Jacobsen have shown subpixel accuracy for Cartosat-1 stereo scenes. ISPRS-ISRO Cartosat-1 Scientific Assessment Programme (C-SAP) Technical report describes results over test areas [15]. YVN Krishna Murthy et.al.(2008) from their analysis have stated that the cartosat-1 imagery are capable of producing topographic maps at 1:25000, thematic maps at 1:10000 and contour map with contour interval of $10 \mathrm{~m} \mathrm{[16].}$ Nelson and Wilson separately describe various DEM production methods and sources in details $[17,18]$. Willneff et al. (2008) has compared the geopositioning accuracy achievable with Cartosat-1 imagery via the $3 \mathrm{D}$ affine, bias-corrected RPC and generic pushbroom sensor models [19]. Singh et al. (2008) has shown results of 5 datasets from Cartosat-1 using RPCs and concluded that RPCs can be provided to the users for photogrammetric processing at their end without compromise on the accuracy [20]. Gorokhovich et al. has shown in their results that absolute average vertical errors from CGIAR dataset can range from $7.58 \pm 0.60 \mathrm{~m}$ to $4.07 \pm 0.47 \mathrm{~m}$ (mean \pm S.E.M.). This is significantly better than a standard SRTM accuracy value (i.e. $16 \mathrm{~m}$ ) [21]. Studies have shown that the vertical accuracy of an ASTER DEM approaches 25 $\mathrm{m}$, but this can improve to $9-11 \mathrm{~m}$ in areas with less vegetation cover [22]. The overall vertical accuracy of open source DEMs such as ASTER and SRTM DEMs has RMS error of $12.62 \mathrm{~m}$ and $17.76 \mathrm{~m}$ respectively, for Dehradun area when compared with Cartosat-1 DEM [23, 24]. The geometric quality of an ortho-imagery depends on the accuracy of the orientation during Epipolar generation, accuracy of ground control points and on the geometric quality and resolution of the used DEM. The accuracy of the primary and secondary DEM derivatives depends on the accuracy of the DEM used to generate or extract these parameters. The determination of exterior orientation parameters is a key element for any kind of imagery from terrestrial, airborne or satellite based sensors. This orientation task traditionally is solved in analytical/analog/digital photogrammetry by aerial triangulation with GPS or Kinematic GPS data [25]. RPC's relate object space to image space and vice versa. Even though no GCP's are available, ground co-ordinates can be derived from image co-ordinates using RPC's. The accuracy of the coordinates depends on the source of RPC's. If GCP's are available one can refine the RPC's using polynomial functions.

\section{Objectives}

The objective of present study is to evaluate the satellite triangulation and the digital surface models (DSMs) generated from Cartosat-1 for varied terrain conditions.

\section{Study Area}

The three sites selected for the study were selected in three different kinds of topography and terrain conditions. A brief description of sites is given below.

\subsection{Dehradun, Uttarakhand Site}

The study area includes the Dehradun city and its surroundings. The general elevation of the area ranges from $450 \mathrm{~m}$ to $2000 \mathrm{~m}$ above mean sea level. Dehradun is the provisional capital city of the Uttarakhand state, India. It is located in the Doon valley, $260 \mathrm{~km}$ north of India's capital New Delhi. The study area is surrounded by the Himalayas in the north, Shivalik Hills in the south, the river Ganga in the east, and the river Yamuna in the west. The water divide of Ganga and Yamuna passes through the city. The study area is characterized by hills and valleys as shown in Figure 1.

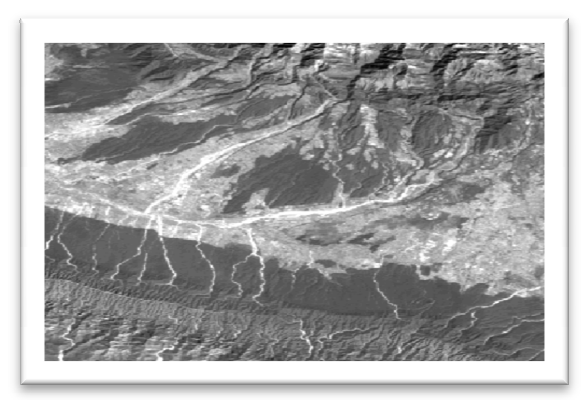

Figure 1. Dehradun \& surroundings (2006, Cartosat-1 aft image)

\subsection{Jaipur, Rajasthan Site}

Jaipur is the capital city of the Rajathan state, India. Figure 2, shows the location map of Jaipur. The stereopair comprises of terrain ranging from plain area, agriculture fields, urban area, waterbody and Aravalli hill range. The data was acquired over Jaipur, on 18 May' 2005.

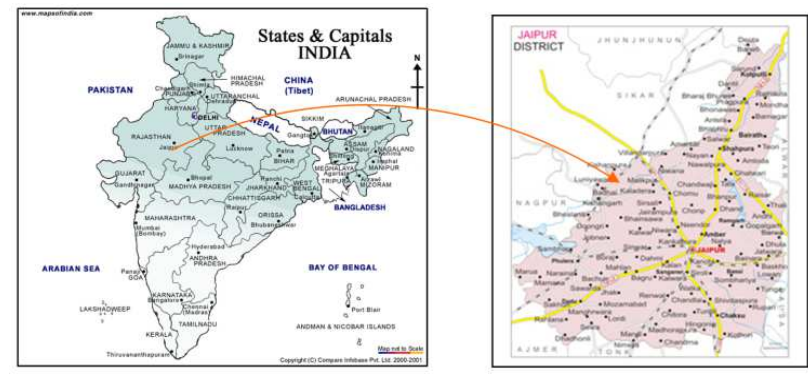

Figure 2. Location map of Jaipur, Rajasthan 


\subsection{Kendrapara, Orissa Site}

Kendrapara District lies in $20^{\circ} 20^{\prime} \mathrm{N}$ To $20^{\circ} 37^{\prime} \mathrm{N}$ Latitude and $86^{\circ} 14^{\prime} \mathrm{E}$ To $87^{\circ} 01^{\prime} \mathrm{E}$ Longitude and situated in central coastal plain zone as per the Agro-Climatic Classification of the Orissa. Four other districts surround Kendrapara District. The District is situated in the north of the Jagatsingpur district, west of the Cuttack District, southwest of the Jajpur District and south of the Bhadrak District. The scene was taken for study under the plain and agriculture area. The area is highly flood prone with extreme hazardous conditions.

\section{Methodology}

The methodology adopted for this study is shown in figure 3. A differential GPS survey was conducted at all the three sites using single frequency Leica GPS 500 System. Planning has been done for uniform distribution of GCPs at all sites. Clearly identifiable sharp points on both the AFT and FORE images were selected as ground control points and observed for measurements using base stations and rovers. The GPS data was post-processed using Leica software to achieve high accuracy. The Cartosat-1 scenes were processesd for satellite triangulation using the ground control points for all the three test sites. These three sites being spread over different UTM zones with varied topography were used to infer the relationship between the topography type and accuracy. A set of points were used as GCPs for satellite triangulation and another set is used as check points. Subsequent to satellite triangulation, DSMs were generated through automatic process in LPS software and analyzed for accuracy in different terrain conditions.

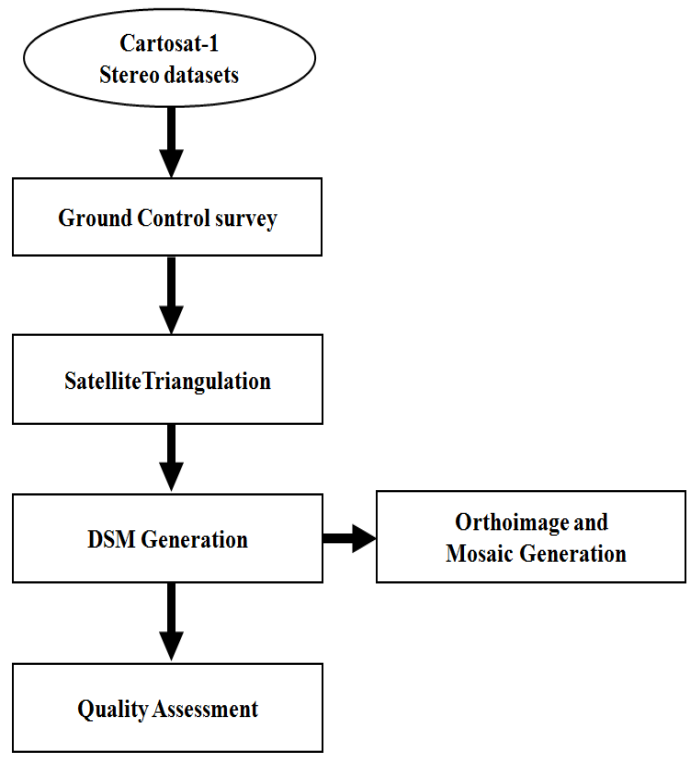

Figure 3. The flowchart of Methodology

\section{Results and Analysis}

\subsection{Satellite Triangulation}

The overall RMSEs (Table 1) for satellite triangulation for the three test sites: Kendrapara, Jaipur, Dehradun has come to 0.501 pixel, 0.753 pixel, and 0.72 , respectively. The digital surface models and orthoimages were generated and are shown below in figure 4. Horizontal accuracies are within a pixel for $\mathrm{X}$ and $\mathrm{Y}$ direction. The vertical accuracy of is within 2-4 pixels depending on the terrain roughness.

Table 1. Summary RMSE for ground control points and check points

\begin{tabular}{|c|c|c|c|c|c|}
\hline S.No. & Study area & $\begin{array}{l}\text { Data } \\
\text { Used } \\
\text { (Path/Row) }\end{array}$ & $\begin{array}{l}\text { No. of } \\
\text { control } \\
\text { points }\end{array}$ & $\begin{array}{l}\text { No. of } \\
\text { check } \\
\text { points }\end{array}$ & RMSE \\
\hline 1. & $\begin{array}{l}\text { Kendrapara, } \\
\text { Orissa }\end{array}$ & $528 / 302$ & 11 & 6 & 0.501 \\
\hline 2. & $\begin{array}{l}\text { Jaipur, } \\
\text { Rajasthan }\end{array}$ & $273 / 520$ & 12 & 6 & 0.753 \\
\hline 3. & $\begin{array}{l}\text { Dehradun, } \\
\text { Uttarakhand }\end{array}$ & $\begin{array}{l}526 / 258 \\
527 / 258\end{array}$ & 20 & 4 & 0.70 \\
\hline
\end{tabular}

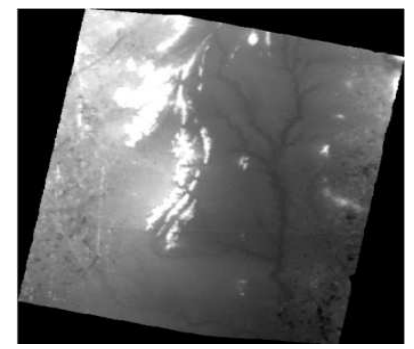

a) DEM (Jaipur site)

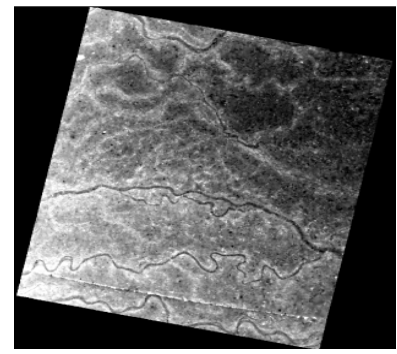

c) DEM (Kendrapara site)

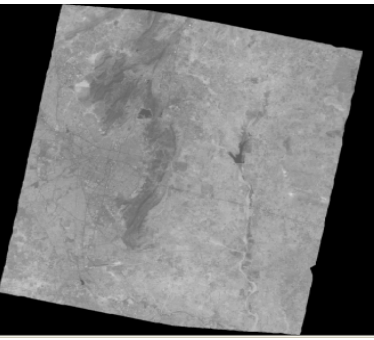

b) Orthoimage (Jaipur site)

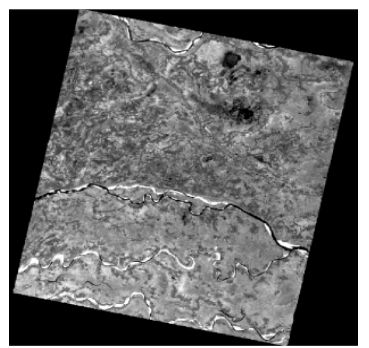

d) Orthoimage (Kendrapara site)

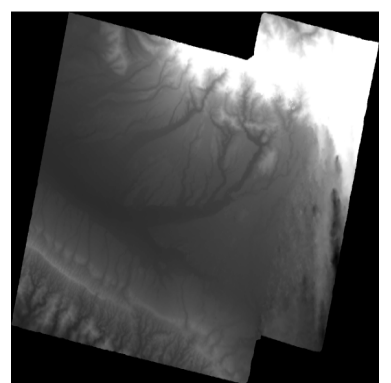

e) DEM (Dehradun site)

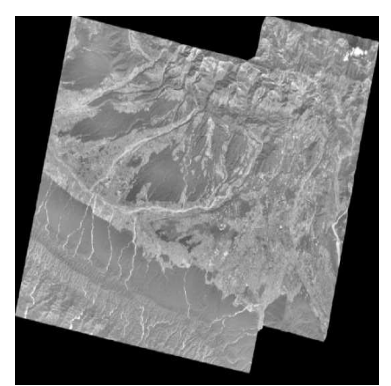

f) Orthoimage (Dehradun site)
Figure 4. DEMs and orthoimages for the three sites 


\subsection{Accuracy assessment of Digital Surface Model}

To validate the accuracies of DSMs generated through Cartosat-1 data the check points measured by DGPS surveying techniques were used. Tables $(2,3$, and 4$)$ give the observations on control points. Accuracy assessment was done by using the check points at all the three sites. Figure 5, shows RMSEs (equation 1) for different terrain types (sites). It reveals that for a plain terrain the RMSE is better than a pixel, for a urban and relatively plain area it is within two pixels. In a highly hilly area like Dehradun, RMSE is above three pixels and less than four pixels. $Z_{(\mathrm{DSM})}$ and $Z_{(\mathrm{DGPS})}$ are the elevation values using the DSM and differential GPS survey respectively.

$$
R M S E=\left[n^{-1} \sum_{i=1}^{n}\left(\mathrm{Z}_{(\mathrm{DGPS})}-\mathrm{Z}_{(\mathrm{DSM})}\right)^{2}\right]^{1 / 2} \ldots \text { equation } 1
$$

Where $\mathrm{n}$ is the number of observation.

Table 2. Shows difference in DSM and DGPS elevation (Dehradun)

\begin{tabular}{|c|c|c|c|}
\hline Point ID & $\mathbf{Z}_{\text {(DGPS) }}$ & $\mathbf{Z}_{\text {(DSM) }}$ & $Z_{\text {(DGPS) }}-Z_{(\text {DSM })}$ \\
\hline 1 & 550.0822 & 551.3629 & -1.280669 \\
\hline 2 & 464.9568 & 459.9175 & 5.039273 \\
\hline 3 & 479.3538 & 481.7321 & -2.378269 \\
\hline 4 & 440.3713 & 439.1867 & 1.184533 \\
\hline 5 & 427.7813 & 429.0768 & -1.295568 \\
\hline 6 & 475.4596 & 474.5103 & 0.949369 \\
\hline 7 & 730.8304 & 734.6276 & -3.797187 \\
\hline 8 & 592.8734 & 591.6462 & 1.227202 \\
\hline 9 & 527.1464 & 527.1631 & -0.016794 \\
\hline 10 & 513.9255 & 516.3663 & -2.440793 \\
\hline 11 & 734.5752 & 730.4836 & 4.091531 \\
\hline 12 & 621.2138 & 620.5668 & 0.646959 \\
\hline 13 & 576.9679 & 574.1219 & 2.845987 \\
\hline 14 & 610.5417 & 610.0467 & 0.495043 \\
\hline 15 & 543.0078 & 541.1225 & 1.885312 \\
\hline 16 & 517.3277 & 518.0052 & -0.677519 \\
\hline 17 & 504.6624 & 504.5548 & 0.107609 \\
\hline 18 & 497.3283 & 498.4792 & -1.150905 \\
\hline 19 & 487.6069 & 485.1017 & 2.505221 \\
\hline 20 & 491.2866 & 490.2747 & 1.011910 \\
\hline
\end{tabular}

Table 3. Shows difference in DSM and DGPS elevation (Jaipur site)

\begin{tabular}{llll}
\hline Point ID & $\mathbf{Z}_{\text {(DGPS) }}$ & $\mathbf{Z}_{\text {(DSM) }}$ & $\mathbf{Z}_{\text {(DGPS) }}-\mathbf{Z}_{(\mathbf{D S M})}$ \\
\hline 1 & 358.19 & 366.21 & -8.02 \\
2 & 324.16 & 327.58 & -3.42 \\
3 & 423.65 & 420.18 & 3.47 \\
4 & 357.39 & 366.54 & $\mathbf{- 9 . 1 4}$ \\
5 & 311.87 & 313.73 & -1.85 \\
6 & 290.72 & 285.52 & 5.20 \\
7 & 301.99 & 298.84 & 3.14 \\
8 & 342.02 & 343.84 & -1.81 \\
9 & 332.62 & 325.62 & 7.00 \\
10 & 316.97 & 310.50 & 6.47 \\
11 & 302.97 & 297.66 & 5.31 \\
12 & 316.06 & 320.24 & -4.18 \\
13 & 375.08 & 374.45 & 0.62 \\
14 & 300.17 & 300.22 & $\mathbf{- 0 . 0 4}$ \\
15 & 327.29 & 327.63 & -0.33 \\
16 & 353.28 & 351.35 & 1.93 \\
17 & 326.92 & 321.56 & 5.36 \\
18 & 286.53 & 278.92 & 7.61 \\
\hline
\end{tabular}

Table 4. Shows difference in DSM and DGPS elevation (Kendrapara site)

\begin{tabular}{llll}
\hline Point ID & $\mathbf{Z}_{\text {(DGPS) }}$ & $\mathbf{Z}_{\text {(DSM) }}$ & $\mathbf{Z}_{\text {(DGPS) }}-\mathbf{Z}_{\text {(DSM) }}$ \\
\hline 1 & -55.49 & -59.13 & 3.64 \\
2 & -54.98 & -55.96 & 0.98 \\
3 & -55.58 & -56.94 & 1.36 \\
4 & -53.46 & -52.83 & -0.63 \\
5 & -51.29 & -54.43 & 3.14 \\
6 & -49.37 & -52.7 & 3.33 \\
7 & -46.74 & -50.81 & 4.07 \\
8 & -52.15 & -53.48 & 1.33 \\
9 & -49 & -51.94 & 2.94 \\
10 & -46.93 & -49.95 & 3.02 \\
11 & -44.76 & -45.56 & 0.8 \\
12 & -45.42 & -41.44 & -3.98 \\
13 & -49.64 & -47.17 & -2.47 \\
14 & -51.14 & -53.26 & 2.12 \\
15 & -54.11 & -53.04 & -1.07 \\
16 & -51.48 & -51.18 & -0.3 \\
17 & -52.44 & -49.46 & -2.98 \\
18 & -52.4 & -50.78 & -1.62 \\
19 & -53.4 & -51.72 & -1.68 \\
20 & -51.83 & -54 & 2.17 \\
\hline
\end{tabular}




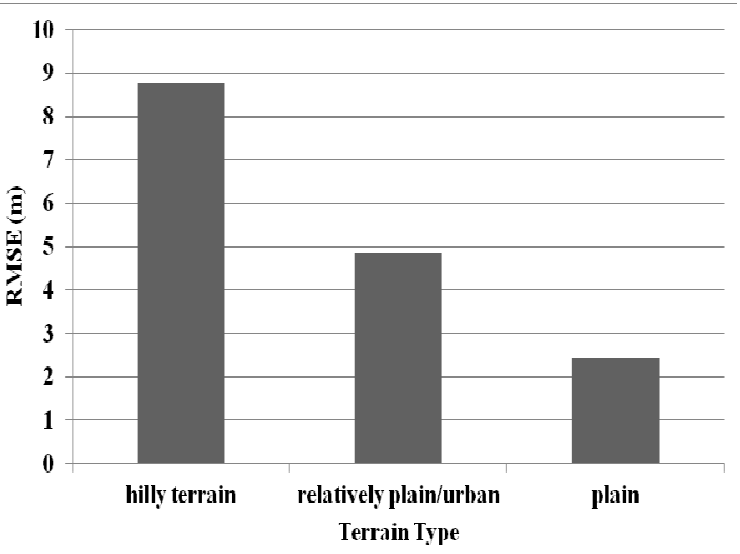

Figure 5. shows RMSE for DSMs generated

The two sites i.e., Jaipur and Dehradun are above the WGS84 datum and thus have positive elevation values. The third site i.e. Kendrapara, Orissa is below the WGS 84 datum and thus have negative elevation values. The EGM values were calculated for third site (Orissa) using equation 2.

\section{$\mathbf{H}=\mathbf{h}-\mathbf{N} \quad$ equation 2}

Where, $\mathrm{H}$ is the orthometric height, $\mathrm{h}$ is ellipsoidal height from GPS and $\mathrm{N}$ is the Geoid height. The orthometric heights were calculated for GCPs at Kendrapara site and analysed using EGM2008 geoid model [26]. The geoid height is averaging to about $62 \mathrm{~m}$ at the control points and is found consistent at kendrapara study area.

\section{Conclusion}

The digital surface models generated from Cartosat -1 stereo data by inclusion of ground control points are highly accurate to 1-2 pixels in planimetry and 1-4 pixels in vertical for plain to rough terrain. The influence of topography is clear from the results of satellite triangulation. The RMSE of satellite triangulation is better than a pixel or nearly a pixel, in all the three sites. Kendrapara, Orissa being the least undulating area among the three sites, has the minimum differences in the DSMs and DGPS elevation values. In all the three studies the observation is that, the accuracy of DSMs generated from Cartosat-1 Stereo data improves highly by use of well distributed GCP's. The geometric accuracy of cartosat-1 data is well suited for topographic mapping for regional planning to local planning.

\section{Acknowledgements}

The author is thankful to Dr. V. K. Dadhwal, Director, National Remote Sensing Centre, Hyderabad who has also been the former Dean, IIRS for his guidance and help during the execution of the presented work. The author also thanks the ever encouraging and guiding forces, the former Director, IIRS Dr. P.S.Roy and Director, IIRS Dr. Y.V.N. Krishna Murthy.

\section{References}

[1] Khoshelham, K. (2005). Region refinement and parametric reconstruction of building roofs by integration of image and height data. International Archives of Photogrammetry and Remote Sensing, IAPRS : XXXVI, part 3 / W 24, 6.

[2] Peter van Blyenburgh, UAVs: an overview Air \& Space Europe, Volume 1, Issues 5-6, September-December 1999, Pages 43-47.

[3] Tapas Ranjan Martha, Detection of landslides by object-oriented image analysis, ITC dissertation number 189 , University of Twente, 2011.

[4] NRSC, 2006. Cartosat-1 data user's handbook. at http://www.nrsc.gov.in/assets/pdf/handbooks/cartosat1.pdf

[5] Ashutosh Bhardwaj, Bayarmaa Enkhtur, S. Rahavendra, Shefali Agrawal, "Topographic Database Generation and 3D Feature Extraction techniques Using Cartosat-1 Stereo Data", XXX INCA International Congress on Cartography for sustainable environment, 10-12 Nov. 2010, Dehradun.

[6] Dial, G. (2000). IKONOS satellite mapping accuracy. ASPRS 2000 Proceedings, Washington DC, 22-26 May 2000.

[7] Grodecki, J and G. Dial (2001). IKONOS geometric accuracy. Proceedings of Joint Workshop of ISPRS WorkingGroups I/2, I/5 and IV/7 on High Resolution Mapping from Space 2001, University of Hanover, Hanover, Germany, Sept 19-21.

[8] Grodecki, J. and G. Dial (2003). Block adjustment of high-resolution satellite images described by rational polynomials. Photogrammetric Engineering \& Remote Sensing, 69(1):59-68.

[9] Grodecki, J. (2001). IKONOS stereo feature extraction - RPC approach. ASPRS 2001 Proceedings, St. Louis, MO, 23-27 April 2001.

[10] Tao, C.V., Hu,Y. and Jiang, W.(2004). Photogrammetric exploitation of IKONOS Imagery for Mapping Application. International Journal of Remote Sensing, 25(14):2833-2853.

[11] Krishnaswamy, M. and S. Kalyanaraman (2004). "Indian Remote Sensing Satellite Cartosat-1: Technical features and data products."

[12] Nadeem, Ahmed., Anjum, Mahtab., Ritesh Agrawal., R, Jayaprasad., S.K., Pathan., Ajai, D.K., SINGH., Anda.K. SINGH,. Extraction and Validation of Cartosat-1 DEM, Journal of the Indian Society of Remote Sensing, Vol. 35, No. 2, 2007

[13] Praveen K. Thakur, Sreyasi Maiti, Nanette C. Kingma, V. Hari Prasad , S. P. Aggarwal, Ashutosh Bhardwaj, 2011, Estimation of structural vulnerability for flooding using geospatial tools in the rural area of Orissa, Natural Hazards (2012) 61: 501-520, March 01, 2012

[14] I.C.Das, Spatial Statistical modelling for assessing landslide hazard and vulnerability, ITC dissertation number 192, University of Twente, 2011.

[15] Jacobsen K., 2006: ISPRS-ISRO Cartosat-1 Scientific Assessment Programme (C-SAP) Technical report - test areas Mausanne and Warsaw, ISPRS Com IV, Goa 2006, IAPRS Vol. 36 Part 4, pp. 1052-1056 
[16] Krishna Muthry, Y.V.N., Srinivasa Rao, S., Prakasa Rao, D.S., Jayaraman V. Analysis of DEM generated using Cartosat-I stereo data over Mausanne les Alphilles - Cartosat scientific appraisal programme (CSAP TS-5). ISPRS 2008, 37, 13431348 .

[17] Nelson, A., Reuter, H.I., Gessler, P., 2009. DEM production methods and sources. In: Hengl, T., Reuter, H.I. (Eds.), Geomorphometry: Concepts, Software, and Applications. Elsevier, Amsterdam, pp. 65-85.

[18] John P. Wilson, Digital terrain modeling, Geomorphology, Volume 137, Issue 1, 15 January 2012, Pages 107-121.

[19] Willneff, J., Weser, T., Rottensteiner, F., and C. S. Fraser (2008). "Precise Georeferencing of Cartosat Imagery via different orientation models", The International Archives of the Photogrammetry, Remote Sensing and Spatial Information Sciences. Vol. XXXVII. Part B1. Beijing 2008

[20] Singh, S. K., Naidu, D. S., Srinivasan, T.P., Krishna, B. G., and P K Srivastava (2008). "Rational polynomial modeling for Cartosat-1 data", The International Archives of the Photogrammetry, Remote Sensing and Spatial Information Sciences. Vol. XXXVII. Part B1. Beijing.

[21] Gorokhovich, Y. and Voustianiouk, A., 2006.Accuracy assessment of the processed SRTM-based elevation data by
CGIAR using field data from USA and Thailand and its relation to the terrain characteristics. Remote Sensing of Environment 104 (2006) 409-415.

[22] Goncalves, J. A. and Oliveira, A. M. (2004) Accuracy analysis of DEM's derived from ASTER imagery. ISPRS XX Commission III WG III/2 - Science Faculty University of Porto, Portugal.

[23] Samadrita Mukherjee, Anirban Mukhopadhyay, Ashutosh Bhardwaj, Arun Mondal, Sananda Kundu, and Sugata Hazra, Digital Elevation Model Generation and Retrieval of Terrain Attributes using Cartosat-1 Stereo Data, International Journal of Science and Technology, Volume 2 No.5, May 2012.

[24] Sandip Mukherjee, P.K. Joshi, Samadrita Mukherjee, Aniruddha Ghosh, R.D. Garg, Anirban Mukhopadhyay, Evaluation of vertical accuracy of open source Digital Elevation Model (DEM), International Journal of Applied Earth Observation and Geoinformation 21 (2013) 205-217

[25] Ashutosh Bhardwaj, Evaluation of DEM, and Orthoimage generated from Cartosat-1 with its potential for feature extraction and visualization, American Journal of Remote Sensing, Vol. 1, Num.1, 2013.

[26] http://geographiclib.sourceforge.net/cgi-bin/GeoidEval (date of access 14.03.2013) 